\title{
sciendo

\section{Mechanical Behaviour of Polylactic Acid Foam as Insulation Under Increasing Temperature}

\author{
Lucia DOYLE ${ }^{1 *}$, Ingo WEIDLICH ${ }^{2}$ \\ ${ }^{1,2}$ HafenCity University, Uberseeallee 16, Hamburg, 20457, Germany
}

\begin{abstract}
Measures to increase the share of renewables in heat generation, combined with increased energy efficiency provide a direct emissions reduction on the heating sector. Energy efficiency measures, as well as the role-out of sustainable heating technologies such as district heating networks have one key actor: insulation. However, state of the art insulating materials such as polyurethane or polystyrene have severe environmental drawbacks incompatible with today's transition to the circular economy, and are the Achilles' heel of the sector in terms of sustainability. Biobased and biodegradable polylactic acid (PLA) foam could be a promising replacement for fossil-based polymeric insulating foams. This study provides data on the mechanical behaviour of expanded PLA foam under different temperatures, which will help to assess its potential use as insulation where the foam is subject to heat.
\end{abstract}

Keywords - Circular economy; insulating foam; Polylactic Acid (PLA); thermal behaviour

\begin{tabular}{|lll}
\hline Nomenclature & & \\
$\sigma_{10}$ & Compressive Stress at 10\% strain & $\mathrm{MPa}$ \\
$E$ & Young Modulus & $\mathrm{MPa}$ \\
$T$ & Temperature & ${ }^{\circ} \mathrm{C}$ \\
$T_{\mathrm{g}}$ & Glass transition temperature & ${ }^{\circ} \mathrm{C}$ \\
$a$ & Sample width & $\mathrm{mm}$ \\
$b$ & Sample depth & $\mathrm{mm}$ \\
$h$ & Sample height & $\mathrm{mm}$ \\
\hline
\end{tabular}

\section{INTRODUCTION}

Energy efficiency measures combined with sustainable renewable sources of heat would significantly reduce global $\mathrm{CO}_{2}$ emissions and contribute to the achievement of goals such as the EU 2020 climate and energy package.

The $4^{\text {th }}$ generation District Heating [1] aims in this direction: by reducing the network's temperature, up to now non-used waste and renewable heat sources can be introduced in the system, significantly contributing to the decarbonisation of the sector, as well as contributing to higher air quality in urban areas. Decreasing the operating temperature will bring higher energy efficiency of the system, and its effects on the system's elements such as the heat

\footnotetext{
* Corresponding author.

E-mail address: lucia.doyle@hcu-hamburg.de 
exchangers have been studied [2]. But the temperature reduction additionally opens up new possibilities in materials selection. This potential remains still untapped.

Today's insulation materials are to a big extent petroleum-based polymeric materials. Polyurethane (PU) and Polystyrene (PS) accounted for $42 \%$ of the European thermal insulation market in 2012 [3], and PU is the standard insulation for District Heating Pipes [4]. However, the environmental profile of these materials makes insulation the weakest point of the sustainability efforts these energy efficiency measures intend to bring.

While PU is chemically inert [5] and non-toxic, its base material isocyanates are toxic and present a number of health and safety issues and harmful effects in varying degrees [5]-[8]. PU is produced from either TDI (toluene diisocyanate) or MDI (methylene diphenyl diisocyanate). TDI and MDI isomers and mixes thereof are classified as suspected of causing cancer, as dermal and respiratory sensitizers, for acute toxicity following inhalation, as well as eye, skin and respiratory irritants [8]. The residual styrene in the PS matrix is carcinogenic, and thus threatening human health [9]. None of these foams is recyclable.

There is an urgent need for developing alternative insulation materials which are nontoxic and fully recyclable, which would support the transition from eco-efficiency to a circular economy.

Within the frame of an exploratory research project aiming at identifying polymeric foams suitable for the insulation of $4^{\text {th }}$ generation district heating networks, the mechanical behavior of PLA foam under different temperatures has been studied in order to obtain information on if and how the foams could be used as insulation in applications where they are subjected to or in contact with higher temperature.

Polylactice acid (PLA) is a thermoplastic aliphatic polyester derived from biomass such as corn starch and sugarcane. It is the best-developed commercially available biopolymer [10] and is currently produced at low cost and commercialized in large quantities [11]. Given its physical properties and biodegradable nature, its first application niche has been biomedical applications, followed by disposable packaging. However, interest and applications concerning the building sector are under development. In 2016 Dutch plastic pipe manufacturer DYKA presented a PLA piping system for housing rain water collection at the VSK trade show (NL), claiming similar properties to PVC and long service life [12]. Previous work on PLA foams have reported comparable behavior with polystyrene foams in terms of mechanical and thermal properties [9], [13]. The PLA foam's intrinsic IR absorbing characteristics, acted via the ester group in the PLA molecular chain, sets this polymer matrix as a good candidate for insulation applications and further enhances its environmental impact [9].

One of the limitations of PLA is its low service temperature, due to its low crystallinity because of its inherently low crystallization kinetics [10], and with a glass transition temperature $\left(T_{\mathrm{g}}\right)$ set around $60{ }^{\circ} \mathrm{C} . T_{\mathrm{g}}$ signals the transition from a hard and relatively brittle state into a rubber like state [14]. There is no clear protocol or parameter to define the heat resistance of a polymer, however, $T_{\mathrm{g}}$ can give an indication of the heat resistance for amorphous or low crystalline polymers [15], [16]. The heat resistance of a material is strongly linked to its crystallinity. A higher degree of crystallinity implies a higher temperature resistance, since the crystalline regions should maintain material stiffness past the $T_{\mathrm{g}}$ [15]. Literature reports the potential of PLA foams to be used at elevated temperatures above its $T_{\mathrm{g}}$, as a higher crystallinity is obtained due to the foaming process, and as a result, the PLA foam products can exhibit ductile and tough behaviour without easy deformation above $T_{\mathrm{g}}$ [10] .

With the basis of the above stated quote, the aim of this study is to observe the mechanical behaviour of readily produced PLA foams above the material's $T_{\mathrm{g}}$, in order to obtain 
information on how and if the foams could be used in applications where they are subjected to or in contact with higher temperature.

\section{Methods And Procedures}

Samples of molded expanded bead PLA foam were provided by BEWiSynbra. Samples where tested for compression in a universal testing machine at a constant strain rate of $2 \mathrm{~mm} / \mathrm{s}$. The plates where placed inside a thermal chamber, where different temperatures can be set. The applied force was a direct output from the testing machine. The strain was optically measured using an ARAMIS adjustable stereo camera system.

The selected test temperatures were $22{ }^{\circ} \mathrm{C}, 55^{\circ} \mathrm{C}, 65^{\circ} \mathrm{C}$ and $75{ }^{\circ} \mathrm{C}$. Samples at $22{ }^{\circ} \mathrm{C}$ were tested after storage for several days at the laboratory's room conditions: $22{ }^{\circ} \mathrm{C}$ and $30 \%$ humidity. Samples tested at higher temperatures were previously temperature soaked inside the thermal chamber. Relative humidity inside the chamber could not be measured or modified and is thought to be very low.

In order to evaluate the impact of the duration of temperature conditioning, a thermocouple was inserted in one sample to measure the time needed to reach $75^{\circ} \mathrm{C}$. It was achieved within minutes. A batch of three samples where tested at $75^{\circ} \mathrm{C}$ after $2 \mathrm{~h}$ temperature conditioning, and 5 further samples after $48 \mathrm{~h}$ of temperature conditioning, showing no difference in behaviour. Therefore, in order to optimize the test execution timing, temperature soaking was $2 \mathrm{~h}$ for the samples at $65^{\circ} \mathrm{C}$ and over night for the samples at $55^{\circ} \mathrm{C}$.

The presented results correspond to the mean of five probes tested for each of the selected temperatures: $22{ }^{\circ} \mathrm{C}, 55^{\circ} \mathrm{C}, 65^{\circ} \mathrm{C}$ and $75^{\circ} \mathrm{C}$.

Samples for the $22^{\circ} \mathrm{C}$ and $75^{\circ} \mathrm{C}$ test series were provided as cut cubes (approx. $48 \cdot 48 \cdot 48 \mathrm{~mm}$ ) by the supplier. Samples for the $55^{\circ} \mathrm{C}$ and $65{ }^{\circ} \mathrm{C}$ were cut out of a slab with the same dimensions as the previous samples using a wire cutter.

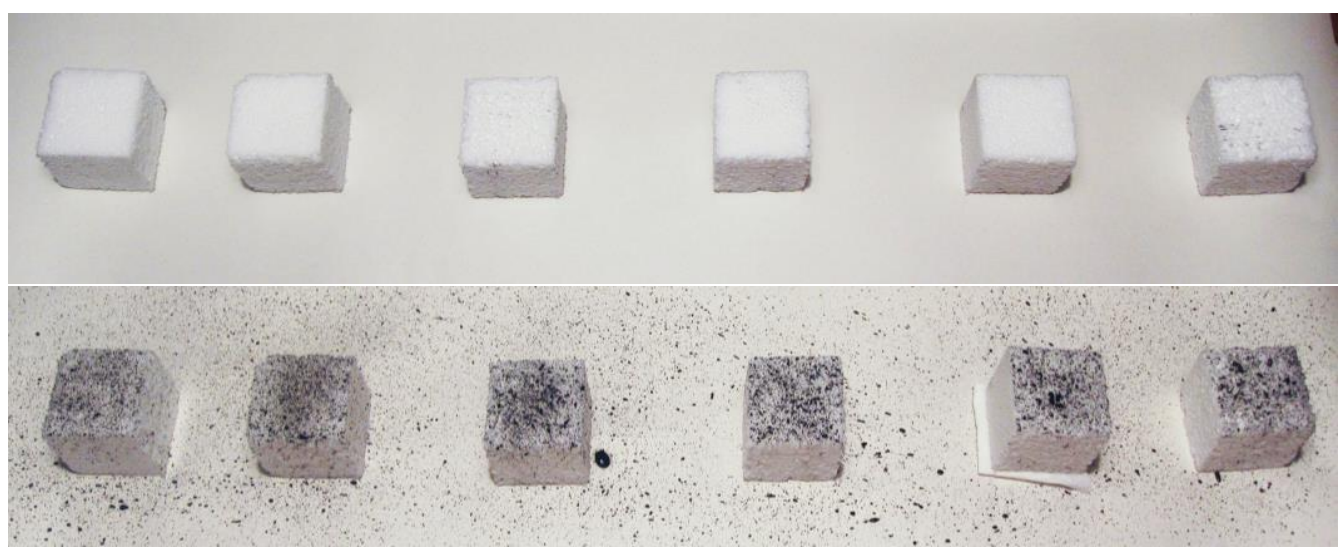

Fig. 1. Sample Preparation: before and after the painting of a stocastical pattern.

Samples where individually accurately measured using caliber and weighed prior testing. After observing shrinkage at $75{ }^{\circ} \mathrm{C}$, samples at $55^{\circ} \mathrm{C}$ and $75^{\circ} \mathrm{C}$ were re-measured after being temperature soaked and immediately before testing. Dimensions of samples tested at $65{ }^{\circ} \mathrm{C}$ were re-evaluated from the images taken from the ARAMIS stereocamera. The strain measured by the ARAMIS optical system's software is based on a stochastic pattern recognition analysis. 
Therefore a stochastical pattern was painted on one side, using canned black spray paint and a toothbrush.

IR spectroscopy has been reported as an appropriate technique to qualitatively and quantitatively determine the degree and nature of crystalline and non-crystalline order and has been previously been used in the study of PLA [16]-[18]. Hence in order to observe changes in the crystallinity structure due to the heating, foam tested under room temperature and under $75^{\circ} \mathrm{C}$ where analysed using a Thermoscientific Nicolet iS 10 FTIR spectrometer.
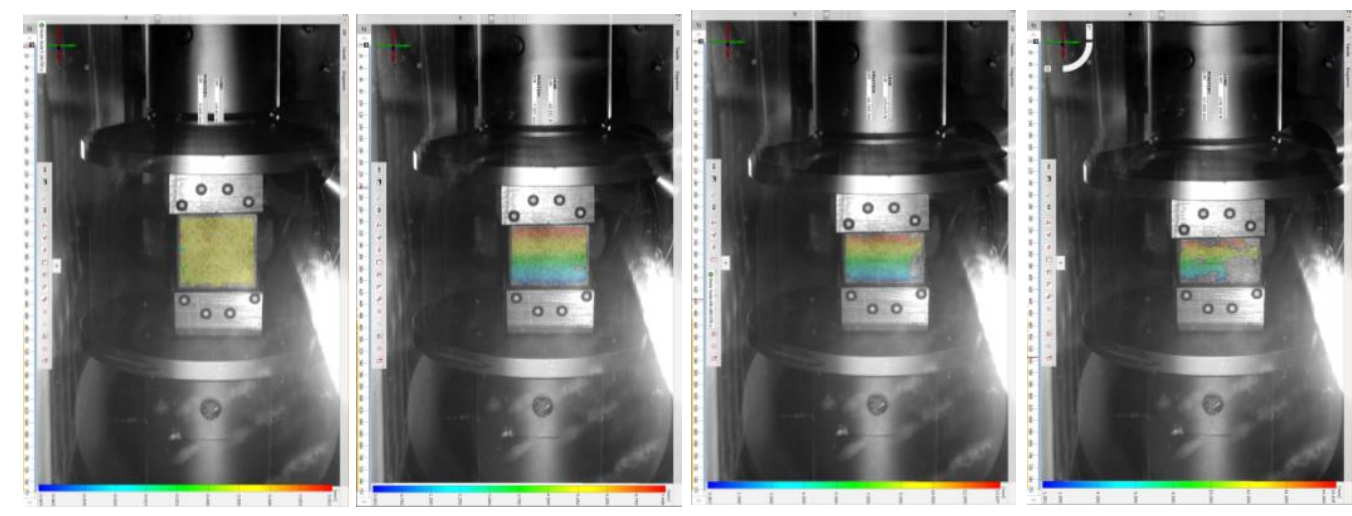

Fig. 2. Visualization of the compression test of sample 75-2. From left to right after 54 s, $272 \mathrm{~s}, 465 \mathrm{~s}$ and $563 \mathrm{~s}$.

\section{RESUlts}

Table one presents the weight and dimensions of each sample, at room and at test temperature.

As can be derived from the data, samples tested at $55^{\circ} \mathrm{C}$ experimented an average volumetric schrinkage of $0.8 \%$ at $55 \%$, of $3.6 \%$ at $65{ }^{\circ} \mathrm{C}$ and of $14.4 \%$ at $75^{\circ} \mathrm{C}$. Schrinkage is typically observed when the gas inside the foam cells diffuses out of the foam in a faster rate as air diffuses in, creating a negative pressure in the closed cells [11].

TABLE 1. SAMPLES WEIGHT AND DiMENSIONS

\begin{tabular}{lllllllll}
\hline & \multicolumn{9}{c}{ At room $\boldsymbol{T},{ }^{\circ} \mathbf{C}$} \\
Sample & ${\text { Test } \mathbf{T}^{\circ}}$ & Weight, $\mathbf{g}$ & $\boldsymbol{a}, \mathbf{~ m m}$ & $\boldsymbol{b}, \mathbf{~ m m}$ & $\boldsymbol{h , ~} \mathbf{m m}$ & $\boldsymbol{a}, \mathbf{~ m m}$ & $\boldsymbol{b}, \mathbf{m m}$ & $\boldsymbol{h}, \mathbf{m m}$ \\
\hline $22-1$ & 22 & 3.44 & 48.3 & 47.9 & 48.7 & 48.3 & 47.9 & 48.7 \\
$22-2$ & 22 & 3.52 & 48.49 & 48.5 & 48.6 & 48.49 & 48.5 & 48.6 \\
$22-3$ & 22 & 3.75 & 48.1 & 50.2 & 48.7 & 48.1 & 50.2 & 48.7 \\
$22-4$ & 22 & 3.41 & 48.16 & 48.12 & 48.03 & 48.16 & 48.12 & 48.03 \\
$22-5$ & 22 & 3.65 & 48.12 & 48.2 & 48.2 & 48.12 & 48.2 & 48.2 \\
$55-1$ & 55 & 3.55 & 48.04 & 48.13 & 48.06 & 48.8 & 47.96 & 47.84 \\
$55-2$ & 55 & 3.35 & 47.99 & 48.2 & 45.85 & 47.96 & 47.85 & 45.88 \\
$55-3$ & 55 & 3.29 & 48.7 & 48.12 & 45.94 & 48.06 & 48.06 & 45.74 \\
\hline
\end{tabular}




\begin{tabular}{lllllllll}
\hline & \multicolumn{9}{c}{ At room $\boldsymbol{T},{ }^{\circ} \mathbf{C}$} & \multicolumn{5}{c}{ At test $\boldsymbol{T},{ }^{\circ} \mathbf{C}$} \\
Sample & Test $\mathbf{T}^{\circ}$ & Weight, $\mathbf{g}$ & $\boldsymbol{a}, \mathbf{~ m m}$ & $\boldsymbol{b}, \mathbf{m m}$ & $\boldsymbol{h , ~} \mathbf{~ m m}$ & $\boldsymbol{a}, \mathbf{m m}$ & $\boldsymbol{b}, \mathbf{m m}$ & $\boldsymbol{h}, \mathbf{m m}$ \\
\hline $55-4$ & 55 & 3.63 & 47.83 & 48.03 & 48.11 & 47.81 & 47.9 & 47.97 \\
$55-5$ & 55 & 3.7 & 48.01 & 48.33 & 47.94 & 47.92 & 47.98 & 47.61 \\
$65-1$ & 65 & 3.58 & 48.37 & 48.7 & 47.78 & 47.70 & 48.02 & 47.12 \\
$65-2$ & 65 & 3.77 & 48.58 & 48.1 & 49.6 & 47.91 & 47.43 & 48.91 \\
$65-3$ & 65 & 3.47 & 48.85 & 48 & 48.12 & 48.12 & 47.29 & 47.41 \\
$65-4$ & 65 & 3.52 & 48.35 & 47.9 & 48.8 & 48.30 & 47.86 & 48.75 \\
$65-5$ & 65 & 3.7 & 48.25 & 48.6 & 48.2 & 47.39 & 47.73 & 47.34 \\
$75-1$ & 75 & 3.49 & 48.22 & 48.23 & 48 & 45.68 & 45.67 & 45.55 \\
$75-2$ & 75 & 3.58 & 48.09 & 48 & 48.1 & 46.2 & 45.39 & 45.04 \\
$75-3$ & 75 & 3.46 & 48.34 & 48.29 & 48.05 & 46 & 45.79 & 47.7 \\
$75-4$ & 75 & 3.64 & 48.02 & 47.97 & 48.1 & 45.25 & 45.23 & 45.36 \\
$75-5$ & 75 & 3.6 & 47.98 & 48.1 & 48.04 & 45.35 & 45.54 & 45.42 \\
\hline
\end{tabular}

The average density for the foam samples is $31 \mathrm{~kg} / \mathrm{m}^{3}$.

Fig. 3 presents the stress strain curves for each sample tested. A clear grouping per test temperature can be observed.

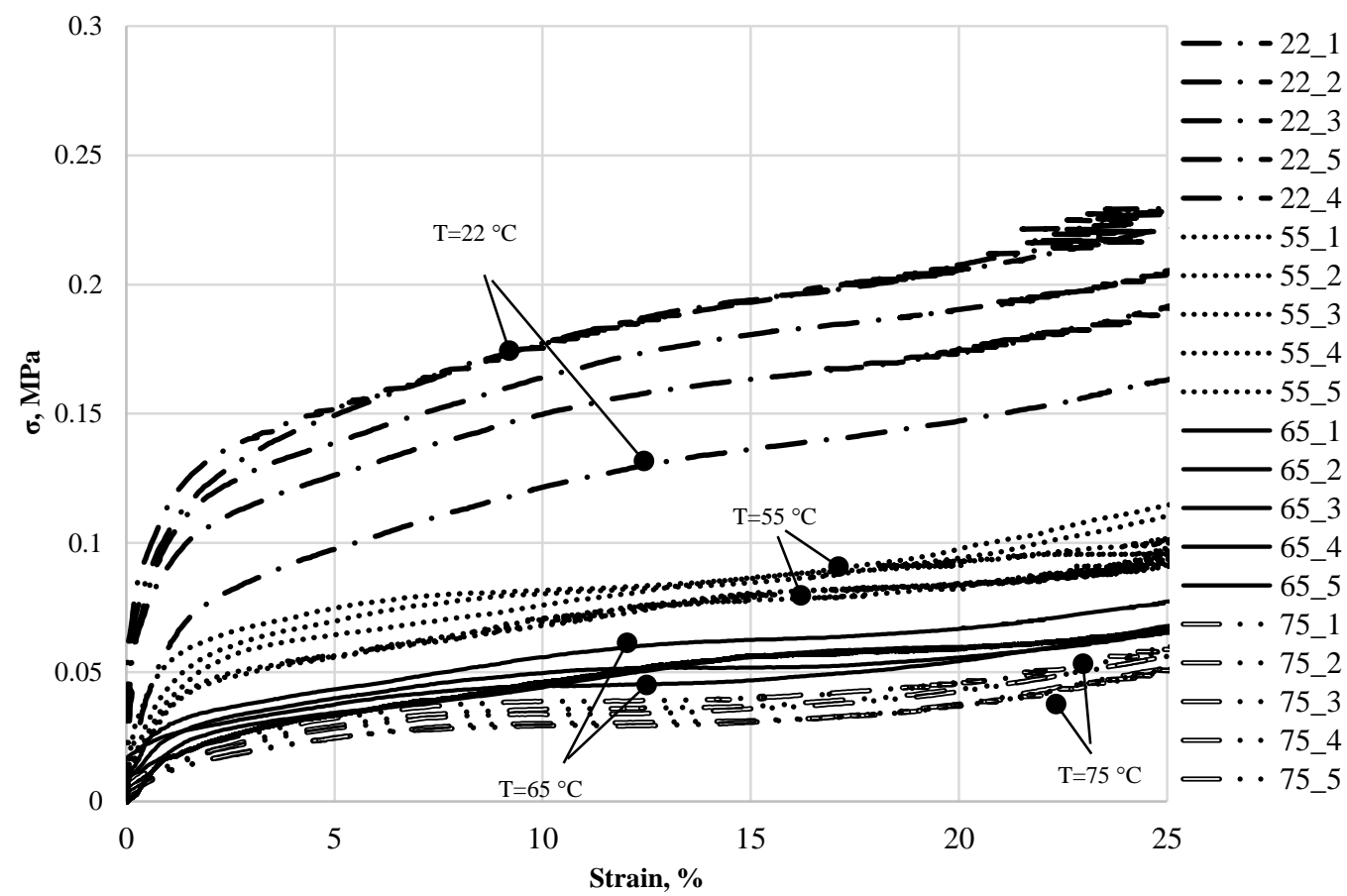

Fig. 3. Stress vs Strain curves for the tested PLA foam samples under different $T$. 
Compressive strength at $10 \%$ strain and $\mathrm{E}$ modulus were calculated for each sample. E modulus was determined for the zone between $25 \%$ and $75 \%$ of $F_{10}$, as per EN ISO 844:2014 [19]. Average values per test temperature and their variance are presented in Table 2.

TABle 2. Calculated Compressive StREngth at $10 \%$ Strain AND E Modulus For EaCH T ${ }^{\circ}$

\begin{tabular}{lllll}
\hline$T,{ }^{\circ} \mathrm{C}$ & $\sigma_{10}, \mathrm{MPa}$ & Variance $\sigma_{10}$ & $\mathrm{E}, \mathrm{MPa}$ & Variance $\mathrm{E}$ \\
\hline 22 & 0.158 & $5.4 \cdot 10^{-4}$ & 0.591 & $4.01 \cdot 10^{-3}$ \\
55 & 0.075 & $4.2 \cdot 10^{-5}$ & 0.298 & $5.23 \cdot 10^{-4}$ \\
65 & 0.048 & $2.2 \cdot 10^{-5}$ & 0.249 & $7.79 \cdot 10^{-4}$ \\
75 & 0.034 & $1.5 \cdot 10^{-5}$ & 0.228 & $4.20 \cdot 10^{-4}$ \\
\hline
\end{tabular}

The relationship of $\sigma_{10}$ and $\mathrm{E}$ with the test temperature can be observed in Fig. 4 and Fig. 5.

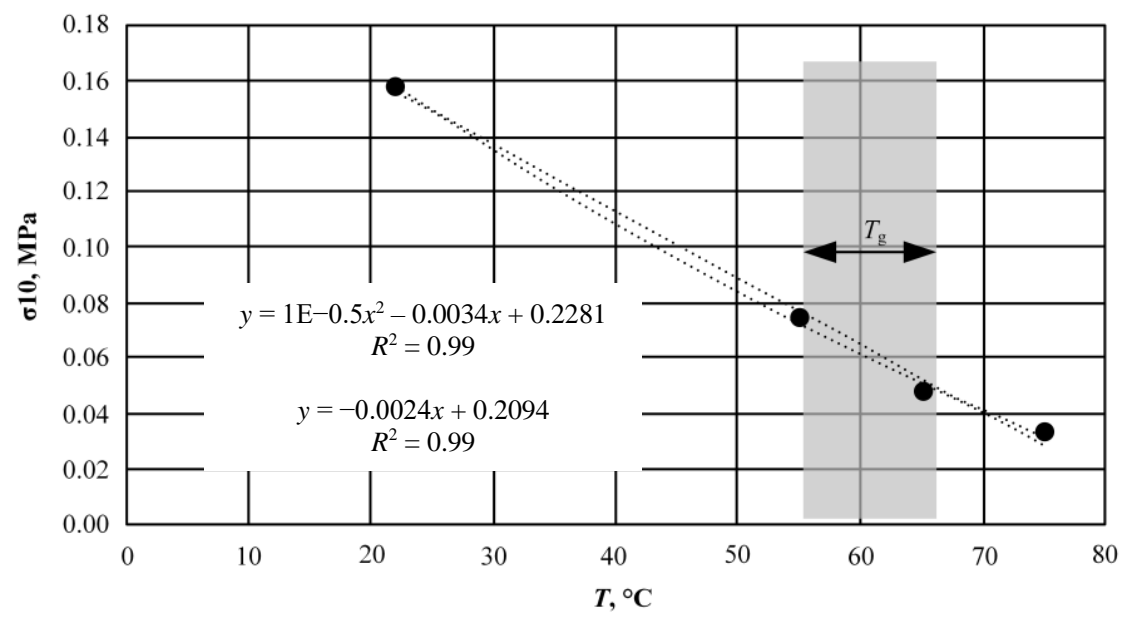

Fig. 4. Relationship of compressive strength with test $\mathrm{T}^{\circ}$.

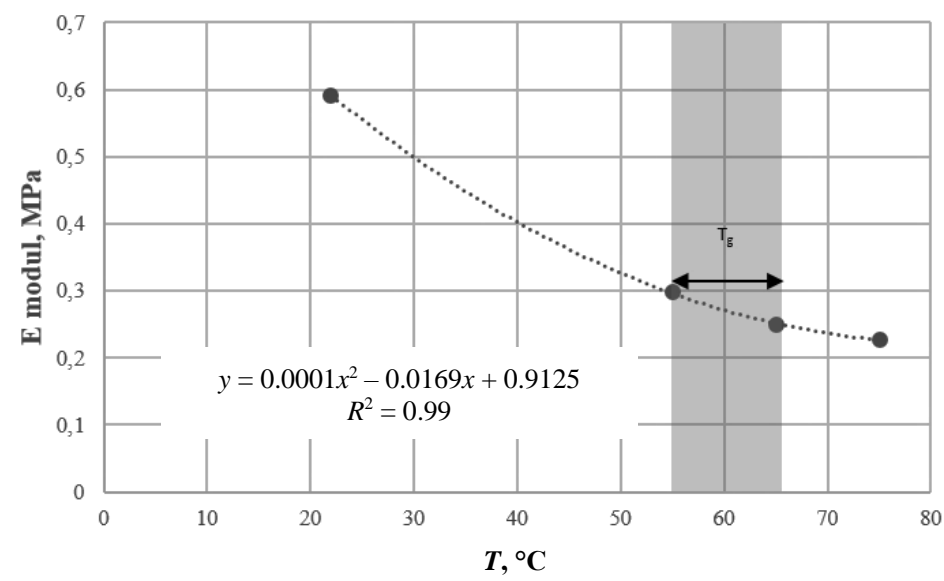

Fig. 5. Relationship of E modulus with test $\mathrm{T}^{\circ}$. 
The obtained IR Spectra of foam samples stored at room temperature $\left(22{ }^{\circ} \mathrm{C}\right)$ and after soaking at $75^{\circ} \mathrm{C}$ is presented in Fig. 6 .

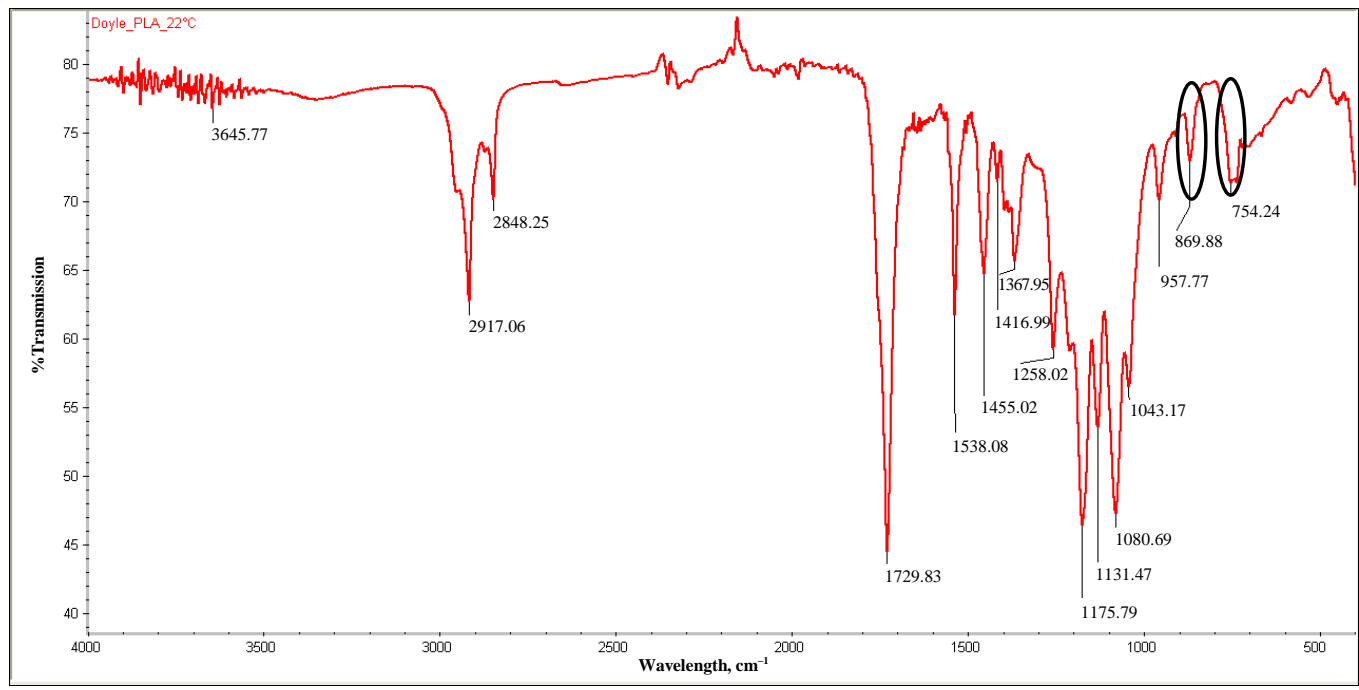

(a)

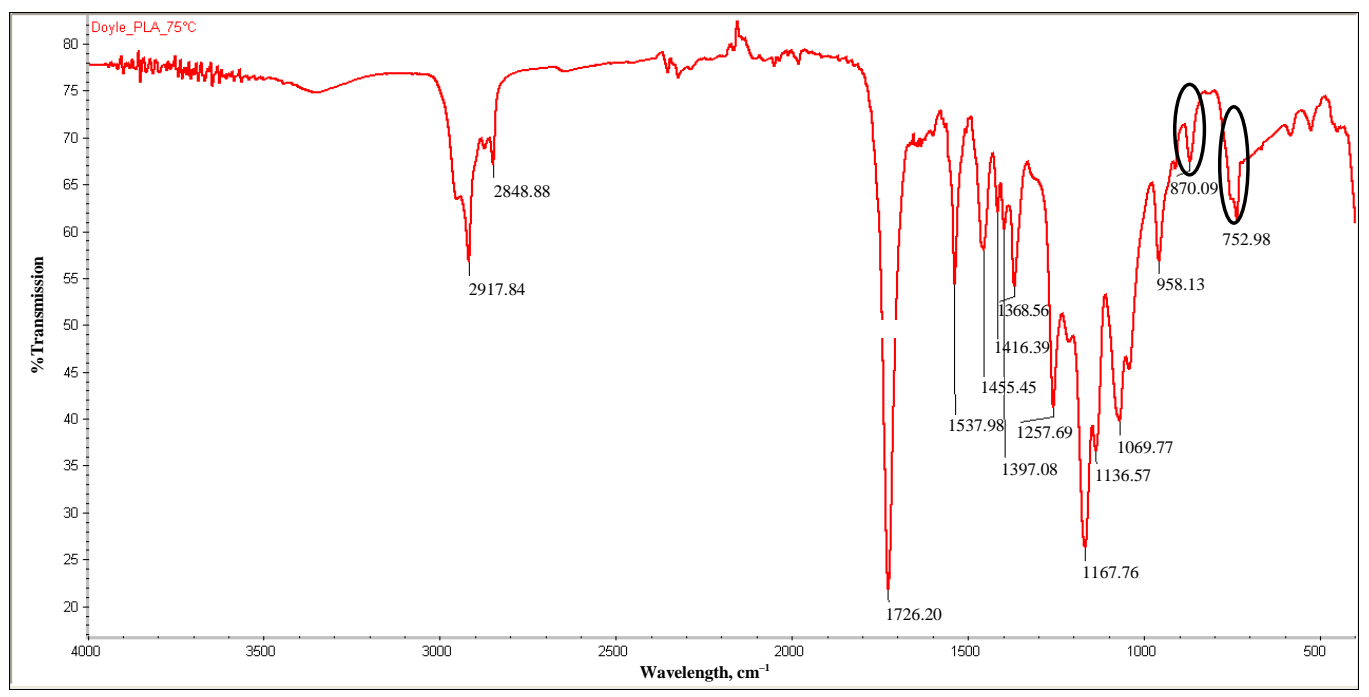

(b)

Fig. 6. IR spectra of PLA foam samples after storage at (a) $22{ }^{\circ} \mathrm{C}$ and (b) $75^{\circ} \mathrm{C}$.

The peaks corresponding to the amorphous and crystalline phases are marked. 


\section{DiscuSSION}

The investigation was carried out with PLA bead foams. Because of the manufacturing process of pre-insulated pipes, the use of bead foam it is not expected, but of extruded foam. However, extruded PLA foams are still under R\&D and not commercially available. Hence, this study intends to provide qualitative data rather than quantitative data as for district heating applications. The generated data is however valuable for other insulating applications requiring foam sheets. Extruded foams would be expected to have a higher density and higher mechanical strength than bead foams. Compared to insulation foams according to district heating standards (PU), the tested material has a half the density, which has an influence on the mechanical properties.

Thus PLA foams would be useful for district heating application operating in the lower temperature levels. In the case of lower temperature, the mechanical strength of the material plays a minor role, since temperature induced stresses and displacements are less significant [20].

The compresive strenght at $10 \%$ strain obtained at room temperature is equivalent to that reported by Parker et al [13]. As expected for a thermoplastic, compression strength and E modulus steadily decreased with the testing temperature. However no sudden drop in properties was observed around the $T_{\mathrm{g}}$. Two correlations are presented for $\sigma_{10}$, linear and quadratic polynomial, as a similar best fit was obtained.

As for the stress strain curve (Fig. 3), an interesting result is that the different samples tested for each temperature presented a larger deviation at room temperature and behaved closer alike as we went up with temperature.

The original crystallinity of the provided foam samples would be between 20 and $30 \%$ according to the manufacturer. Work from Auras et al. [16] and Younes and Cohn, compiled in [21], report a peak related to the crystalline phase, at $755 \mathrm{~cm}^{-1}$ in [21] and $756 \mathrm{~cm}^{-1}$ in [16], and to the amorphous phase, at $869 \mathrm{~cm}^{-1}$ in [21] and $871 \mathrm{~cm}^{-1}$ in [16]. Consistent with these studies, both peaks were found and identified in our work. Crystallization of the amorphous but thermally crystallizable PLA copolymers is reported to be initiated by annealing at temperatures starting at $75{ }^{\circ} \mathrm{C}$ [16]. Since this temperature corresponds to the higher testing temperature of this work, determining if further crystallization occurs due to the operation temperature the insulation is subjected to would provide valuable information about the aging of the foam. Further work on the preparation of a standard curve is needed to allow for quantitative determination of each phase. Further research is needed to evaluate the potential impact of thermal cycling.

Since the processing of PLA is still in its infancy, an increase of heat and mechanical stability is possible through further research and control on crystalization kinetics.

\section{CONCLuSions}

This study provides data that can be used for the simulation of systems where the insulating foam is subject or in contact with temperature, in order to assess the suitability of PLA for given applications. As expected for a thermoplastic, compression strength and E modulus steadily decreased with the testing temperature. However no sudden drop in properties was observed around the $T_{\mathrm{g}}$.

Further research is needed to determine the effects of thermal cycling on PLA insulating foam. 
This study is based on a limited number of specimens. Further research is necessary to get a more profund insight in the thermal behaviour of this biodegradable insulation material.

\section{ACKNOWLEDGEMENT}

Assistance provided by Marcus Illguth and his staff at HCU on the execution of the experiments is greatly appreciated. Jürgen de Jong at BEWiSynbra is gratefully acknowledged for providing the PLA bead foam samples.

\section{Author Contribution}

L. Doyle was responsible for the study design and conception, data colection and analysis and chiefly responsible for preparing the manuscript. I. Weidlich provided scientific supervision of the study. Both authors contributed with the critical discussion of the results and editing of the manuscript.

\section{REFERENCES}

[1] Lund H., et al. 4th Generation District Heating (4GDH) Integrating smart thermal grids into future sustainable energy systems. Energy 2014:68:1-11. doi:10.1016/j.energy.2014.02.089

[2] Vigants, E., et al. Modelling of Technological Solutions to $4^{\text {th }}$ Generation DH Systems. Environmental and Climate Technologies 2017:20(1):5-23. doi:10.1515/rtuect-2017-0007

[3] IAL Consultants. The European Market for Thermal Insulation Products. Press Release, 2013.

[4] EN 253:2009 District heating pipes - Preinsulated bonded pipe systems for directly buried hot water networks - Pipe assembly of steel service pipe, polyurethane thermal insulation and outer casing of polyethylene.

[5] Dernehl C. U. Health hazards associated with polyurethane foams. Journal of Occupational Medicine 1966:8(2):59-62.

[6] Zapp Jr. J. A. Hazards of Isocyanates in Polyurethane Foam Plastic Production. Archives of Industrial Health 1957:15(4):324-330.

[7] US Department of Labor [Online]. [Accessed 19.11.2018]. Available: https://www.osha.gov/SLTC/isocyanates/

[8] Annex XV Restriction Report - Proposal for a restriction to ECHA by BAuA. Vers 2.1, 2017.

[9] Gong P., et al. Environmentally-friendly Polylactic Acid-based Thermal Insulation Foams Blown with Supercritical $\mathrm{CO}_{2}$. Industrial and Engineering Chemistry Research 2018:57(15):5464-5471. doi:10.1021/acs.iecr.7b05023

[10] Nofar M., Park C. B. Polylactide Foams. Fundamentals, Manufacturing and Applications. Elsevier, 2018. doi:10.1016/C2017-0-00939-4

[11] Reignier J., Gendron R. Champagne M. F. Extrusion Foaming of Poly(Lactic acid) Blown with $\mathrm{CO}_{2}$ : Toward $100 \%$ Green Material. Cellular Polymers 2007:26(2):83-115. doi:10.1177/026248930702600202

[12] Bioplastics Magazine. DYKA premieres world's first plastic pipe system from renewably-sourced plant-based material [Online]. [Accessed 03.02.2016] Available:

https://www.bioplasticsmagazine.com/en/news/meldungen/2016-02-03-DYKA-lauches-bioplastic-pipe-system.php

[13] Parker K., Garancher J. P., Shah S., Fernyhough A. Expanded polylactic acid - an eco-friendly alternative to polystyrene foam. Journal of Cellular Plastics 2011:47(3):233-243. doi:10.1177/0021955X11404833

[14] ISO 11357-2:2013 Plastics - Differential scanning calorimetry (DSC) - Part 2: Determination of glass transition temperature and glass transition step height.

[15] Peelman N., et al. Heat resistance of new biobased polymeric materials, focusing on starch, cellulose, PLA and PHA. Journal of Applied Polymer Science 2015:132(48): 42305. doi:10.1002/app.42305

[16] Auras R., Harte B., Selke, S. An overview of Polylactides as Packaging Materials. Macromolecular Bioscience 2004:4(9):835-864. doi:10.1002/mabi.200400043

[17] Kister G., Cassanas G., Vert M. Effects of morphology, conformation and configuration on the IR and Raman spectra of various poly(lactic acids)s. Polymer 1998:39(2):267-273. doi:10.1016/S0032-3861(97)00229-2

[18] Kister G., et al. Vibrational Analysis of Poly(L-lactic acid). Journal of Ramanan Spectroscopy 1995:26(4):307-311. doi:10.1002/jrs.1250260409

[19] EN ISO 844:2014 Rigid cellular plastics - Determination of compression properties.

[20] Weidlich I. Sensitivity analysis on the axial soil reaction due to temperature induced pipe movements. Presented at the 15th International Symposium on District Heating and Cooling, Seoul, South Korea, 2016.

[21] Garlotta D. A Literature Review of Poly(Lactic Acid). Journal of Polymers and the Environment 2001:9(2):63-84. doi:10.1023/A:1020200822435 